\title{
PLANEAMIENTO ESTRATÉGICO EN EL SECTOR PÚBLICO
}

La implementación del Planeamiento Estratégico en las organizaciones del estado de los países de América Latina, se origina en el programa "Alianza para el Progreso" creada por iniciativa del Ex Presidente de EEUU, J.F. Kennedy, como una herramienta para contrarrestar la influencia de la Revolución Cubana y apoyar medidas reformistas para el desarrollo económico y social.

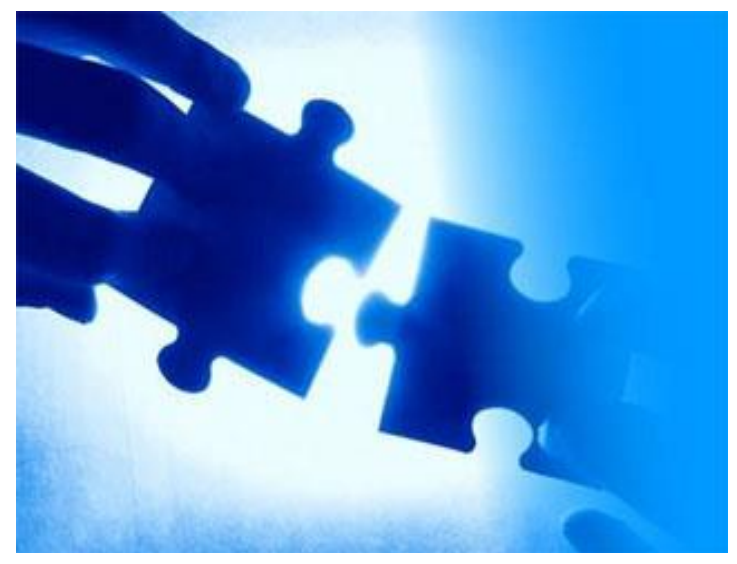

Este programa fue aprobado en el año 61 , en una reunión organizada por el Consejo Interamericano Económico de la Pera (CIE) en Punta del Este (Uruguay) donde asisten todos los países que integraban esta organización, incluyendo Cuba quien fue el país que no aprueba la declaración y carta en la cual se establece que Estados Unidos, proporciona apoyo económico a los países de América Latina, siempre que estos cumplan con formular sus planes decanales, la modernización de la industria, la reforma agraria y otras medidas.

A raíz de este hecho los países de América Latina, crearon dentro de su estructura orgánica del Estado una entidad encargada de realizar el
Planeamiento para el Desarrollo del País, en el Perú la Junta Militar de 1962, crea el Instituto Nacional de Planificación, siendo en el año 1963 con el presidente de ese momento Fernando Belaunde de Terry, donde se da inicio e importancia a esta entidad del estado, enviando a funcionarios a capacitarse a fin de implementar el Sistema de Planificación Nacional. Durante el Gobierno Revolucionario de 1968 a 1980, el Instituto Nacional de Planificación centraliza su planeamiento en tres grandes objetivos: 1. Reforma Educativa 2. Reforma Agraria 3. Modernización de las FFAA.

En 1980, siendo Presidente el Arquitecto Don Fernando Belaunde de Terry, impulsa al Instituto Nacional de Planificación con un plan de gobierno integral y con una visión compartida, pero no contaba con el inicio de la Lucha Subversiva que duro todo su gobierno y el primer gobierno del Doctor Alan García Pérez, donde esta entidad no podía cumplir sus funciones ya que los Planes y Presupuestos se convirtieron en reactivos, se empleaban de acuerdo a la situación del momento.

En el año 1992, siendo Presidente el Ingeniero Alberto Fujimori Fujimori, desactiva esta dependencia, pasando las funciones al Ministerio de Economía y Finanzas, por lo que los presupuestos respondían a programas de acuerdo a las prioridades establecidas por gobierno. Sin embargo en el año 2000 el Ministerio de Economía y Finanzas, dispone que los diferentes sectores elaboren sus Planes Estratégicos Sectorial Multianual $2000-2005$ (PESEM) con la finalidad de que los presupuestos respondan a los objetivos 
establecidos por los sectores respectivos.

A partir del 2001 el ex presidente Alejandro Toledo Manrique, dispone que el Ministerio de Economía y Finanzas elabore una directiva para dictar los lineamientos necesarios para la elaboración del PESEM 2001 - 2006. Simultáneamente en el año 2002 convoco a los líderes de los partidos políticos, de las organizaciones sociales e instituciones religiosas para suscribir el Acuerdo Nacional con la finalidad de establecen objetivos que orienten los gastos del estado. En este acuerdo nacional se establece la creación del Centro Nacional de Planeamiento Estratégico (CEPLAN), el cual se creó en el año 2003, esta entidad ha presentado una Matriz del Plan Perú 2021 que contiene 149 lineamientos de política nacional, 29 prioridades, 31 objetivos específicos, 77 indicadores y metas, 221 acciones estratégicas y 61 programas estratégicos, los mismos que se encuentran a nivel de validación para su posterior promulgación y aplicación en todos los sectores del Perú.

A la fecha se sigue efectuando los Planes Sectoriales Multianuales, (PESEM) dirigido por el Ministerio de Economía y Finanzas, el cual es el ente del gobierno que centraliza los Planes Estratégicos de Mediano Plazo (5 años) tiempo que dura cada gobierno. Es necesario que el CEPLAN, asuma su responsabilidad por ser la dependencia encargada de establecer los objetivos y metas de todos los sectores y priorice para la distribución presupuestaria. 